\title{
Altered nitroxidergic and NMDA receptor-mediated modulation of baroreflex-mediated heart rate in obese Zucker rats
}

\author{
Jwo-Sheng Chen ${ }^{1}$, Hui-Ju Wang ${ }^{1}$, Weng-Cheng Chang ${ }^{2}$, Chin-Ci Jao ${ }^{3}$, Bor-Tsang Wu ${ }^{4,7}$, Woei-Cherng Shyu ${ }^{5,7}$ \\ and Shin-Da Lee $\mathrm{L}^{4,6,7}$
}

Arterial baroreflex, an important physiological regulatory system for buffering systemic blood pressure, is impaired in obesity. This study investigated whether the blunted baroreflex function in obesity is attributed to the altered nitroxidergic or $N$-methyl-Daspartate (NMDA) mechanism. Baroreflex bradycardia responses, blood pressure and heart rate in $\mathbf{3 0}$ lean and $\mathbf{3 0}$ obese anesthetized Zucker rats (8-12 weeks of age) were assessed after injecting phenylephrine with intravenous preadministration of saline (control), dextromethorphan (DXM, NMDA receptor antagonist, $10 \mathrm{mg} \mathrm{kg}^{-1}$ ) or $N(G)$-nitro-L-arginine methyl ester (L-NAME, nitric oxide synthase inhibitor, $100 \mathrm{mg} \mathrm{kg}^{-1}$ ). Compared with lean rats $\left(-2.00 \pm 0.29\right.$ b.p.m. $\left.\mathrm{mm} \mathrm{Hg}^{-1}\right)$, the baroreflex sensitivity (BRS) in obese rats $\left(-0.43 \pm 0.05\right.$ b.p.m. $\mathrm{mm} \mathrm{Hg}^{-1}$ ) was significantly blunted. The BRS was significantly suppressed by DXM in lean rats but not in obese rats. After administration of L-NAME, BRS was significantly suppressed in lean Zucker rats but not in obese Zucker rats. The normal BRS was significantly suppressed in lean rats after administration of both DXM and L-NAME, and the blunted BRS in obesity was significantly blocked to nearly no BRS after administration of both DXM and L-NAME. This study suggests that BRS is blunted in obese rats and that blunted baroreflex is, at least in part, attributed to altered nitroxidergic or NMDA receptor-mediated modulation.

Hypertension Research (2010) 33, 932-936; doi:10.1038/hr.2010.109; published online 17 June 2010

Keywords: baroreceptor; blood pressure; glutamate; heart rate; nitric oxide

\section{INTRODUCTION}

Baroreflex has an important role in maintaining cardiovascular homeostasis through a negative feedback loop that regulates blood pressure levels and heart rate (HR). ${ }^{1-2}$ The baroreflex response is typically initiated by changes in blood pressure or volume that stimulate arterial baroreceptors located in the carotid sinus and aortic arch. ${ }^{1}$ The impulses triggered by arterial baroreceptors are propagated through the glossopharyngeal and vagus nerves to the nucleus tractus solitarii of the medulla, resulting in inhibition of the sympathetic system and activation of the parasympathetic system. ${ }^{3-4}$

Baroreflex sensitivity (BRS) has often been reported to be impaired or reduced in normotensive obese subjects, ${ }^{5}$ hypertensive patients with central obesity, ${ }^{6}$ obese women, ${ }^{7}$ young and older obese men, ${ }^{8}$ and obese patients with metabolic syndrome. ${ }^{9}$ The underlying mechanism of baroreflex attenuation in obesity is not yet well known; however, there is increasing evidence that it is at least partly related to autonomic nervous system dysfunction and particularly to the sympathetic overactivity that accompanies obesity. ${ }^{10}$ The obese Zucker rat, a genetic model of morbid obesity, presents many of the same deficits as those noted in obese humans, including hypertension, ${ }^{11}$ cardiac remodeling, ${ }^{12}$ impaired baroreflex, ${ }^{13}$ impaired chemoresponse ${ }^{14-16}$ and poor exercise capacity. ${ }^{17-18}$ Enhanced central sympathetic discharge, abnormal hemodynamics and attenuated BRS were found in obese Zucker rats. ${ }^{19-20}$ Even normotensive, obese Zucker rats have impaired chronotropic baroreflexes. ${ }^{20}$ The blunted baroreflex may contribute to initial blood pressure elevation and further cause hypertension in obesity. ${ }^{20-21}$ It is important to note that reduced baroreflex sensitivity, which is common in obesity, may contribute to the increased risk of cardiovascular disease and represents a negative prognostic factor in cardiovascular diseases. ${ }^{7,9}$

Neurotransmission or neuromodulation has a crucial role in the processing of neural signals for coordinating arterial baroreflex control. ${ }^{22}$ The neuromodulatory effect of nitroxidergic and glutamatergic transmission has been reported to be involved in baroreflex regulation. ${ }^{23-24}$ The $N$-methyl-D-aspartate (NMDA)-mediated mechanism has an important role in the mechanism of baroreflex. ${ }^{23}$

${ }^{1}$ Department of Sports Medicine, China Medical University, Taichung, Taiwan; ${ }^{2}$ Graduate Institute of Medical Science, Chang Jung Christian University, Tainan, Taiwan; ${ }^{3}$ Graduate Institute of Medical Science, China Medical University, Taichung, Taiwan; ${ }^{4}$ Department of Physical Therapy, Graduate Institute of Rehabilitation Science, China Medical University, Taichung, Taiwan; ${ }^{5}$ Department of Neurology and Graduate Institute of Immunology, Center for Neuropsychiatry, China Medical University and Hospital, Taichung, Taiwan and ${ }^{6}$ Department of Healthcare Administration, Asia University, Taichung, Taiwan

${ }^{7}$ These authors contributed equally to this work.

Correspondence: Professor, S-D Lee, Department of Physical Therapy, Graduate Institute of Rehabilitation Science, China Medical University, 91 Hsueh-Shih Road, Taichung 40202, Taiwan.

E-mail: shinda@mail.cmu.edu.tw

Received 27 September 2009; revised 13 April 2010; accepted 25 April 2010; published online 17 June 2010 
The gain of baroreflex bradycardia is reduced by the microinjection of NMDA receptor antagonists. ${ }^{25}$ A previous study suggested that nitric oxide (NO) has a physiologically significant neuromodulatory role in baroreflex regulation. ${ }^{24}$

Adult obese Zucker rats have elevated sympathetic vasomotor tone and arterial pressure and blunted sympathetic baroreceptor reflexes compared with adult lean Zucker rats. ${ }^{13}$ Our previous studies indicate that altered glutamatergic mechanisms exerting an effect on NMDA receptors, as well as nitroxidergic mechanisms, are partially responsible for blunted chemoresponses in obese Zucker rats. ${ }^{15,26}$

Whether the abnormal BRS observed in obese Zucker rats is associated with altered NMDA receptor-mediated modulation and/or nitroxidergic modulation has not been previously studied. We hypothesized that the altered BRS in obese Zucker rats is mediated by altered glutamatergic NMDA and nitroxidergic modulation. We used dextromethorphan (DXM), a noncompetitive NMDA receptor antagonist, and $N(\mathrm{G})$-nitro-L-arginine methyl ester (L-NAME), a nitric oxide synthase inhibitor, to investigate whether downregulated endogenous glutamate and NO modulate BRS in obese Zucker rats. A parallel study design was used, with age-matched wild-type lean Zucker rats serving as controls.

\section{METHODS}

\section{Animals}

The studies were conducted on 30 obese (fa/fa) and 30 age-matched lean wildtype $(\mathrm{Fa} / \mathrm{Fa}$ or $\mathrm{Fa} / \mathrm{fa})$ male Zucker rats. Animals were bred using female $(\mathrm{Fa} / \mathrm{fa})$ and male $(\mathrm{Fa} / \mathrm{fa})$ breeders purchased from the Charles River Lab in France (Charles River Lab, L'Arbresle, France). One lean and one obese rat were studied at the same age (approximately $8-12$ weeks old) and on the same day. Ambient temperature was maintained at $25^{\circ} \mathrm{C}$ and the animals were kept on an artificial 12-h light-dark cycle. The light period began at 0700 hours. Rats were provided with standard laboratory chow (Lab Diet 5001; PMI Nutrition International, Brentwood, MO, USA) and water ad libitum. All protocols were approved by the Institutional Animal Care and Use Committee of China Medical University, Taichung, Taiwan.

\section{Surgical preparation}

All rats were anesthetized with $\alpha$-chloralose-urethane (initial dose $50 \mathrm{mg} \mathrm{kg}^{-1}$ $\alpha$-chloralose and $500 \mathrm{mg} \mathrm{kg}^{-1}$ urethane, Sigma Chemical, St Louis, MO, USA) dissolved in distilled water and injected intraperitoneally. Adequate anesthesia was administered by infusion of $10 \mathrm{mg} \mathrm{kg}^{-1} \alpha$-chloralose and $100 \mathrm{mg} \mathrm{kg}^{-1}$ urethane (intravenously), when needed. The disappearance of pedal reflexes indicated adequate anesthesia. The rat was placed supine on a small table and secured by tying its four limbs. A middle incision was made in the neck region. The pretracheal muscle was retracted to expose the trachea and a transverse incision was made between two rings. A cannula was introduced into the opening to allow free breathing without obstruction. The temperature of the rat's hot pad was maintained at $35-36^{\circ} \mathrm{C}$. The left femoral artery was exposed and a polyethylene catheter (PE50, Becton Dickinson, Sparks, MA, USA) filled with heparin solution $\left(500 \mathrm{IU} \mathrm{ml}^{-1}, \mathrm{v} / \mathrm{v}\right)$ was inserted into the artery through a small incision to record arterial blood pressure. The catheters were attached to a 23 -gauge needle connected by a three-way stopcock to a pressure transducer. Femoral veins of both limbs were cannulated to inject drugs.

\section{Arterial blood pressure and HR recording}

Before recording arterial blood pressure, the catheter was flushed with heparinized saline solution $\left(500 \mathrm{IU} \mathrm{ml}^{-1}, \mathrm{v} / \mathrm{v}\right)$ to prevent the formation of blood clots, which might interfere with the normal recording of arterial blood pressure. The blood pressure recording system was calibrated with the help of a mercury manometer before each experiment. Arterial blood pressure was monitored continuously using a cannula inserted into the femoral artery and connected by a pressure transducer (model P23-ID, Gould Instruments, Cleveland, $\mathrm{OH}, \mathrm{USA}$ ). The signals recorded from the pressure transducer were amplified with a pressure processor amplifier (Gould 20-4615-52). The amplified signals were recorded on a PowerLab acquisition system ( $\mathrm{AD}$ Instruments, Colorado Springs, CO, USA). Blood gases and $\mathrm{pH}$ were monitored for the arterial blood sample, which was analyzed using a blood gas analyzer (Rapidlab 348, Bayer, Medfield, MA, USA) in the beginning and after the final recording, and were within normal limits. Arterial blood pressure was measured after a 20-min stabilization period. Systolic, diastolic, mean arterial pressure and HR were recorded on the PowerLab data acquisition system (4SP, AD Instruments, Castle Hill, Australia) with a computerized analysis program.

\section{Measurement of BRS}

BRS was measured by administering vasoconstrictor phenylephrine (750-1500 ng salt per $100 \mathrm{~g}$ body weight per $\mathrm{min}$ ) for $1 \mathrm{~min}$ through a venous catheter. The resultant changes in HR at the corresponding rise in systolic blood pressure of approximately $30-40 \mathrm{~mm} \mathrm{Hg}$ were measured continuously. The relationship between the increase in systolic blood pressure evoked by phenylephrine and associated bradycardia was assessed by the ratio of peak change in HR to peak change in mean blood pressure (MBP) for the individual animal. BRS regression (several points of MBP and HR) was carried out for most of the lean and obese Zucker rats for the purpose of calibration before or after the experimental protocol. We plotted BRS regression to confirm the ratio of peak change in HR to peak change in MBP when given a single phenylephrine administration.

\section{Experimental protocol}

After surgical preparation and calibration, one lean and one obese Zucker rat on the same day using BRS as the baseline at $10 \mathrm{~min}$ after the infusion of saline (control). After the complete recovery of blood pressure and HR in $30 \mathrm{~min}$, the BRS of rats was determined again $10 \mathrm{~min}$ after the infusion of DXM $\left(10 \mathrm{mg} \mathrm{kg}^{-1}\right)$ or L-NAME $\left(10 \mathrm{mg} \mathrm{kg}^{-1}\right)$ through the vein. After complete recovery of blood pressure and $\mathrm{HR}$ in another $30 \mathrm{~min}$, baroreflex sensitivities in rats were reassessed $10 \mathrm{~min}$ after the infusion of L-NAME $\left(10 \mathrm{mg} \mathrm{kg}^{-1}\right)$ or DXM $\left(10 \mathrm{mg} \mathrm{kg}^{-1}\right)$ through the vein to observe the effect of DXM plus L-NAME. All solutions were prepared daily. To minimize potential differences, each rat was tested at approximately the same time during the day.

The experimental protocol for BRS with the infusion of DXM $(n=20)$ and then with the addition of L-NAME is as follows:

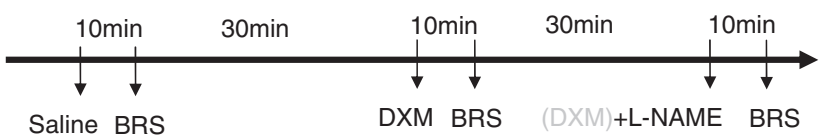

The experimental protocol for BRS with the infusion of L-NAME $(n=10)$ and then with the addition of DXM is as follows:

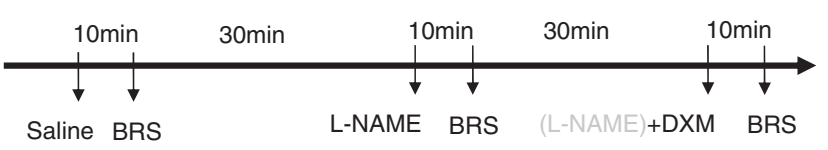

\section{Statistical analysis}

The body weights of lean and obese Zucker rats were averaged in all experiments, and differences between the two groups were tested by unpaired Student's $t$-test. The other parameters (MBP, HR, body temperature, $\Delta \mathrm{HR} / \triangle \mathrm{MBP}$ ) were analyzed by analysis of variance using the general linear model in a one-between (lean and obese) and one-within (saline and drug) design. Differences in BRS-related parameters among saline (control), DXM, L-NAME and DXM plus L-NAME were subsequently tested as single-group repeated measures with contrast transformation against control in lean or obese Zucker rats, separately. The contrast transformation is useful when one level of the repeated measures is a control level (saline) against the other level (DXM, L-NAME or DXM plus L-NAME). In all cases, $P<0.05$ was considered statistically significant. All data presented in the text, tables and figures are means \pm s.e.m.

\section{RESULTS}

Body weights in obese Zucker rats were significantly higher than those in lean rats (Table 1). Body temperature, MBP and HR of the lean and 
obese groups did not differ (Table 1). Body temperature, MBP and HR did not change after DXM infusion for either the lean or the obese Zucker rats (Table 2). Body temperature and HR did not change after L-NAME or DXM plus L-NAME infusion for either the lean or the obese Zucker rats. MBP in obese Zucker rats was significantly increased after L-NAME or DXM plus L-NAME infusion, but this change was not found in lean rats (Table 2).

BRS stimulated by phenylephrine in obese Zucker rats was significantly reduced compared with lean rats (Figure 1). BRS was significantly reduced after DXM infusion in lean but not in obese Zucker rats (Figure 2). BRS was significantly reduced after L-NAME infusion in lean but not in obese Zucker rats (Figure 3). BRS was significantly suppressed in lean rats after infusing both DXM and L-NAME. The blunted BRS in obesity was significantly blocked to nearly no BRS after administration of both DXM and L-NAME (Figure 4). Representative changes in BRS in lean and obese Zucker rats after vehicle (control), DXM infusion, L-NAME infusion and coexistent DXM and L-NAME infusion were shown in Figure 5.

\section{DISCUSSION}

Our findings can be summarized as follows: (1) The phenylephrineinduced BRS-mediated HR reduction in obese Zucker rats was significantly blunted compared with that in lean rats. (2) BRS was significantly suppressed by DXM in lean rats but not in obese Zucker rats. (3) After infusion of L-NAME, the BRS was significantly suppressed in lean but not in obese Zucker rats. (4) BRS was significantly suppressed in lean rats after infusion of both DXM and L-NAME, whereas the blunted BRS in obese Zucker rats was suppressed to nearly no BRS after infusion of both DXM and L-NAME. Our findings imply

Table 1 Basic characteristics, blood pressure and heart rate in lean and obese Zucker rats

\begin{tabular}{lcc}
\hline & Lean $(\mathrm{n}=30)$ & Obese $(\mathrm{n}=30)$ \\
\hline BW $(\mathrm{g})$ & $162 \pm 6$ & $225 \pm 11^{* *}$ \\
BT $\left({ }^{\circ} \mathrm{C}\right)$ & $35.3 \pm 0.4$ & $35.4 \pm 0.3$ \\
MBP (mm Hg) & $108 \pm 2$ & $105 \pm 4$ \\
HR (b.p.m.) & $350 \pm 14$ & $323 \pm 12$
\end{tabular}

Abbreviations: $\mathrm{BT}$, body temperature; $\mathrm{BW}$, body weight; $\mathrm{HR}$, heart rate; MBP, mean blood presure; $n$, number of the participants.

Data presented as mean \pm s.e.

${ }^{* *} P<0.01$, significant difference between lean rats and obese Zucker rats. that the blunted BRS in obesity is, at least in part, attributed to altered nitroxidergic or NMDA receptor-mediated modulation.

Glutamate, an excitatory neurotransmitter, has an important role in the central mechanisms of baroreflex sensitivity. ${ }^{27-28}$ Glutamate activates ionotropic NMDA ( $N$-methyl-D-aspartate) and non-NMDA

Table 2 Basic characteristics, blood pressure, and heart rate in lean and obese Zucker rats before and after DXM, L-NAME and DXM plus L-NAME administration

\begin{tabular}{|c|c|c|c|c|}
\hline \multirow[b]{3}{*}{$\mathrm{n}$} & \multicolumn{4}{|c|}{$D X M$} \\
\hline & \multicolumn{2}{|c|}{ Lean $(\mathrm{n}=20)$} & \multicolumn{2}{|c|}{ Obese $(n=20)$} \\
\hline & Before & After & Before & After \\
\hline BW (g) & \multicolumn{2}{|c|}{$160 \pm 9$} & \multicolumn{2}{|c|}{$240 \pm 15^{*}$} \\
\hline $\mathrm{BT}\left({ }^{\circ} \mathrm{C}\right)$ & $35.6 \pm 0.6$ & $35.4 \pm 0.3$ & $35.8 \pm 0.6$ & $35.7 \pm 0.5$ \\
\hline $\mathrm{MBP}(\mathrm{mm} \mathrm{Hg})$ & $107 \pm 2$ & $102 \pm 4$ & $103 \pm 5$ & $102 \pm 6$ \\
\hline \multirow[t]{4}{*}{ HR (b.p.m.) } & $358 \pm 9$ & $333 \pm 22$ & $326 \pm 16$ & $319 \pm 19$ \\
\hline & \multicolumn{4}{|c|}{ L-NAME } \\
\hline & \multicolumn{2}{|c|}{ Lean $(\mathrm{n}=10)$} & \multicolumn{2}{|c|}{ Obese $(n=10)$} \\
\hline & Before & After & Before & After \\
\hline BW (g) & \multicolumn{2}{|c|}{$170 \pm 8$} & \multicolumn{2}{|c|}{$230 \pm 12^{*}$} \\
\hline $\mathrm{BT}\left({ }^{\circ} \mathrm{C}\right)$ & $36.3 \pm 0.5$ & $36.2 \pm 0.4$ & $36.8 \pm 0.6$ & $36.9 \pm 0.5$ \\
\hline $\mathrm{MBP}(\mathrm{mm} \mathrm{Hg})$ & $114 \pm 8$ & $127 \pm 11$ & $110 \pm 5$ & $145 \pm 3^{\#}$ \\
\hline HR (b.p.m.) & $280 \pm 17$ & $248 \pm 11$ & $272 \pm 7$ & $268 \pm 15$ \\
\hline
\end{tabular}

L-NAME+DXM or DXM+L-NAME

\begin{tabular}{|c|c|c|c|c|}
\hline \multirow[b]{2}{*}{$\mathrm{n}$} & \multicolumn{2}{|c|}{ Lean $(n=30)$} & \multicolumn{2}{|c|}{ Obese $(n=30)$} \\
\hline & Before & After & Before & After \\
\hline BW (g) & \multicolumn{2}{|c|}{$163 \pm 8$} & \multicolumn{2}{|c|}{$236 \pm 14^{*}$} \\
\hline BT $\left({ }^{\circ} \mathrm{C}\right)$ & $35.5 \pm 0.6$ & $35.4 \pm 0.8$ & $35.6 \pm 0.8$ & $35.6 \pm 0.6$ \\
\hline $\mathrm{MBP}(\mathrm{mm} \mathrm{Hg})$ & $114 \pm 7$ & $120 \pm 10$ & $112 \pm 5$ & $125 \pm 4^{\#}$ \\
\hline HR (b.p.m.) & $340 \pm 15$ & $314 \pm 13$ & $302 \pm 10$ & $278 \pm 11$ \\
\hline
\end{tabular}

Abbreviations: BT, body temperature; BW, body weight; DXM, dextromethorphan; L-NAME, N(G)nitro-L-arginine methyl ester; HR, heart rate, $n$, number of subjects; MBP, mean blood pressure nitro-L-arginine methyl ester;

${ }^{*} P<0.05$, significant difference between lean rats and obese Zucker rats

$\# P<0.05$, significant difference between the values before (that is, vehicle) and after drug (that is, DXM, L-NAME, or DXM plus L-NAME) infusion.

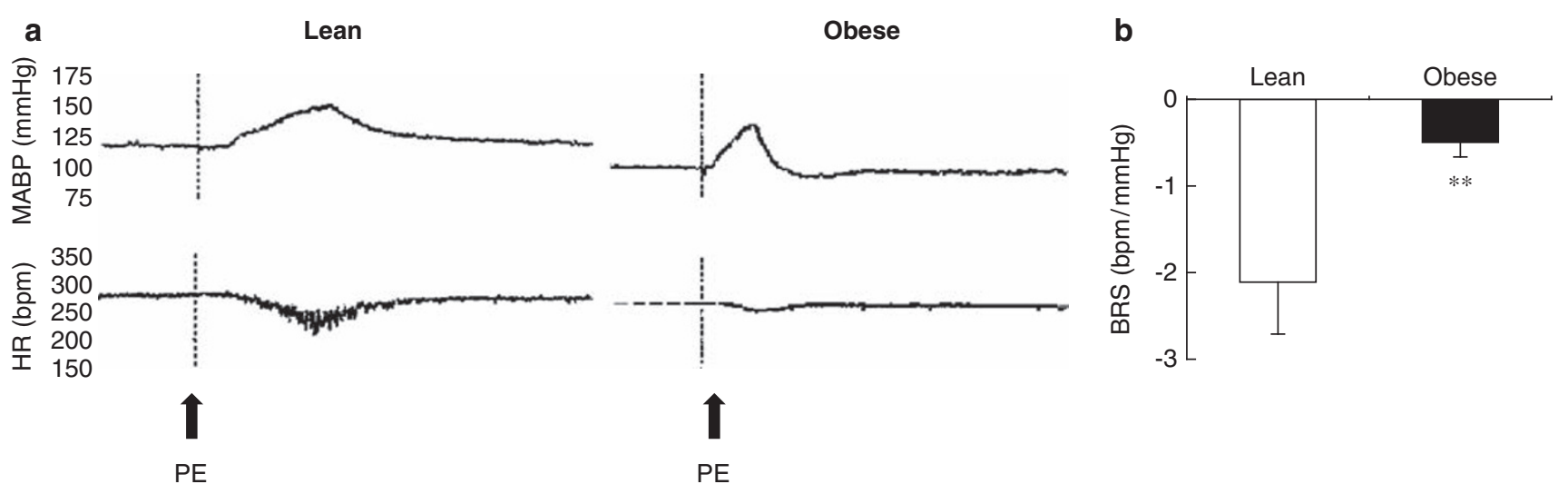

Figure 1 (a) Representative changes in MBP and HR in lean and obese Zucker rats after phenylephrine (PE) injection. (b) Average BRS in lean and obese Zucker rats ( $n=30,30$, respectively). ${ }^{* *} P<0.01$; significant difference between lean rats and obese Zucker rats. 
( $\alpha$-amino-3-hydroxy-5-methyl-4-isoxazolepropionic acid and kainate) receptors, as well as metabotropic receptors, all of which have been shown to be involved in the modulation of BRS. ${ }^{27-29}$ Studies have found that the NMDA and NO modulation processes of chemoreceptor reflexes are impaired in obese Zucker rats ${ }^{15,26}$ and the chemoreceptor reflex control interacts with baroreflex. ${ }^{30}$ A previous study

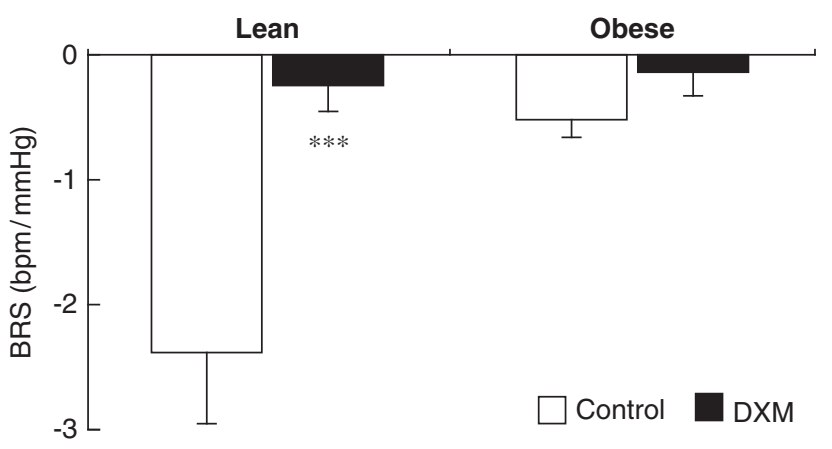

Figure 2 Average BRS in lean and obese Zucker rats $(n=10,10$, respectively) after vehicle (control) or DXM infusion. $* * * P<0.001$; significant difference between vehicle (control) and DXM.

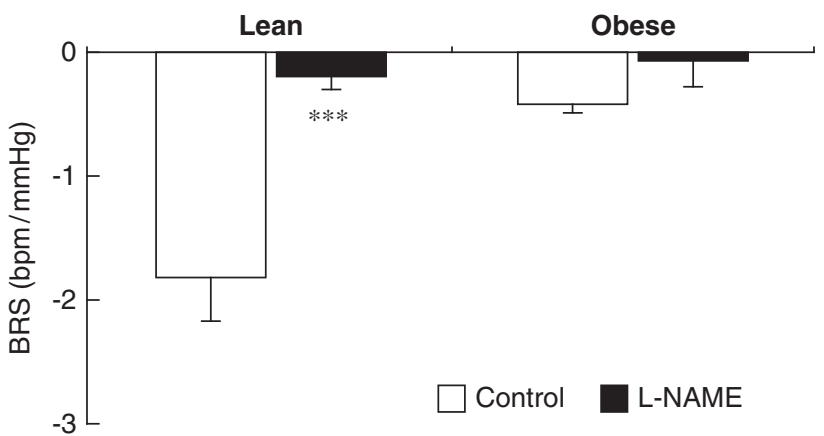

Figure 3 Average BRS in lean and obese Zucker rats $(n=20,20$, respectively) after vehicle (control) or L-NAME infusion. ${ }^{* * *} P<0.001$; significant difference between vehicle (control) and L-NAME. showed that the gain of the baroreflex-mediated bradycardia is reduced by the microinjection of NMDA receptor antagonists into the nucleus tractus solitarii. ${ }^{25}$ In this study, the baroreflex-mediated bradycardia was remarkably reduced by the intravenous infusion of DXM in lean rats but not in obese Zucker rats. The present finding that NMDA-mediated modulation of baroreflex was blunted in obese but not in lean Zucker rats implies that this altered NMDA-mediated modulation of baroreflex might, at least in part, be attributed to obesity in these animals.

A previous study indicated that the inhibition of nitric oxide synthase within the nucleus tractus solitarii attenuated baroreflex, suggesting that NO might have a physiologically significant neuromodulatory role in baroreflex regulation. ${ }^{24}$ In this study, the baroreflex-mediated bradycardia was remarkably reduced by intravenous infusion of L-NAME in lean rats but not in obese Zucker rats. The findings based on the effects of nitric oxide synthase inhibitor in lean and obese Zucker rats implied that NO-mediated baroreflex bradycardia was normally modulated by endogenous NO in lean rats,

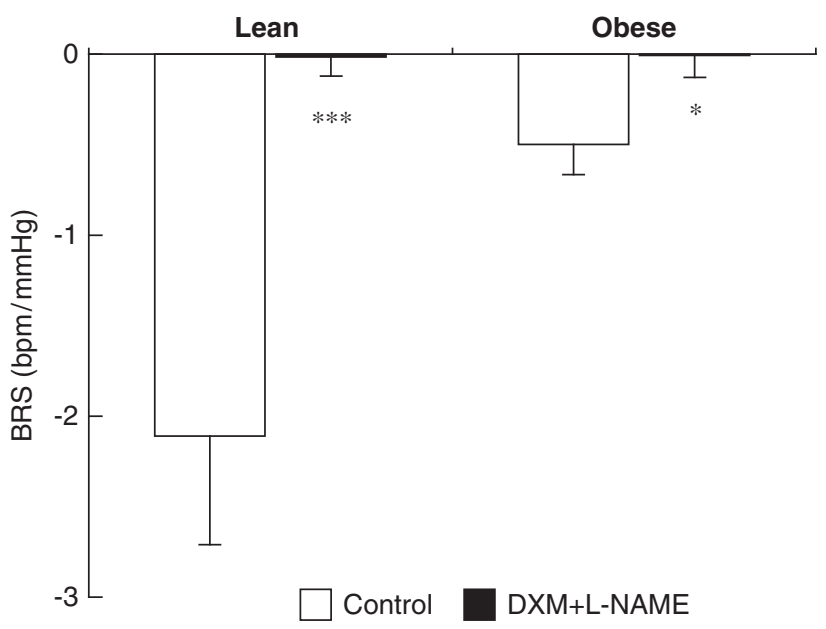

Figure 4 Average BRS in lean and obese Zucker rats $(n=30,30$, respectively) after vehicle (control) or coexistent DXM and L-NAME infusion. ${ }^{*} P<0.05,{ }^{* *} P<0.001$; significant difference between vehicle (control) and DXM plus L-NAME.

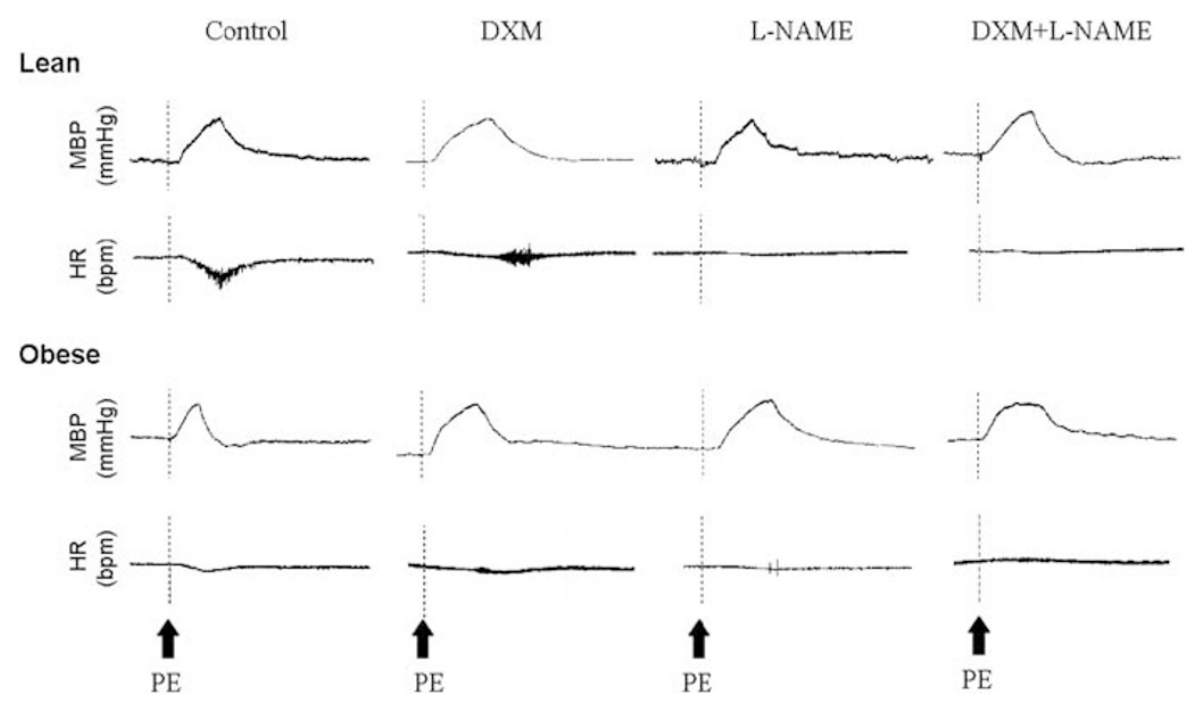

Figure 5 Representative changes in MBP and HR in lean and obese Zucker rats after phenylephrine (PE) injection after vehicle (control), DXM infusion, L-NAME infusion and coexistent DXM and L-NAME infusion. 
whereas nitroxidergic modulation of baroreflex in obesity was blunted. The altered nitroxidergic modulation might, at least in part, be attributed to the blunted BRS in obesity.

The activation of glutamatergic receptors in the brain or NTS elicits the production and release of $\mathrm{NO}$ and other neurotransmitters or neuromodulators. ${ }^{31}$ The release of NO facilitates glutamatergic transmission in the brain or NTS and induces NMDA receptor activation. ${ }^{24,31}$ The interaction of glutamatergic and nitroxidergic modulation regulates baroreflex-mediated heart rate. ${ }^{24,31}$ In this study, the blunted BRS in obesity was significantly blocked to nearly no BRS after administration of both DXM and L-NAME. The findings suggest that the blunted BRS in obesity was mediated by the coeffects of NO and NMDA.

Furthermore, potential interactions among obesity, anesthetic agents and experimental drugs, and potential interactions between chemoreflexes and baroreflexes, may affect our results. Although there are interactions between peripheral chemoreflexes and baroreflexes in animals and humans, ${ }^{32-33}$ to our knowledge, the interactions between chemoreceptor reflexes and baroreflexes in obese Zucker rats remain unknown. Thus, any effect noted herein after DXM or L-NAME infusion may be caused by indirect factors and could not be localized to a specific location or system. The purpose of this study, however, was to determine whether downregulated glutamatergic or nitroxidergic modulation is generally responsible for the blunted BRS in obesity.

\section{Significance}

Arterial baroreceptors have important roles in the short-term regulation of arterial pressure through reflex chronotropic effects on the heart and in the reflex regulation of sympathetic outflow to the vessels. ${ }^{10}$ Blunted BRS in obese animals and humans also represents a negative prognostic factor in cardiovascular diseases and may lead to long-term cardiovascular mortality. ${ }^{7,34}$ The development of blunted BRS in obesity is insidious and may often be overlooked because patients are typically free of complaints. Our current finding that the blunted BRS in obese Zucker rats is, at least in part, attributed to altered nitroxidergic or NMDA receptor-mediated modulation provides a possible explanation for the development of blunted BRS in obesity. Clinically, when considering possible therapeutic agents to control or prevent the development of blunted BRS in obesity, special attention should be paid to the actions of glutamatergic and nitroxdergic modulation on baroreflex responses in morbidly obese humans.

\section{ACKNOWLEDGEMENTS}

This study is supported in part by the Taiwan Department of Health Clinical Trial and Research Center of Excellence (DOH99-TD-B-111-004), by the National Science Council (NSC98-2314-B-039-002) and by China Medical University (CMU98-CT-23).

1 Fan W, Reynolds PJ, Andresen MC. Baroreflex frequency-response characteristics to aortic depressor and carotid sinus nerve stimulation in rats. Am J Physiol 1996; 271: H2218-H2227.

2 Staessen J, Fiocchi R, Fagard R, Hespel P, Amery A. Progressive attenuation of the carotid baroreflex control of blood pressure and heart rate during exercise. Am Heart $J$ 1987; 114: 765-772.

3 Biaggioni I, Whetsell WO, Jobe J, Nadeau JH. Baroreflex failure in a patient with central nervous system lesions involving the nucleus tractus solitarii. Hypertension 1994; 23: 491-495.

4 Zanzinger J, Czachurski J, Seller H. Effects of nitric oxide on sympathetic baroreflex transmission in the nucleus tractus solitarii and caudal ventrolateral medulla in cats. Neurosci Lett 1995; 197: 199-202.

5 Grassi G, Dell'Oro R, Facchini A, Quarti Trevano F, Bolla GB, Mancia G. Effect of central and peripheral body fat distribution on sympathetic and baroreflex function in obese normotensives. J Hypertens 2004; 22: 2363-2369.
6 Del Colle S, Milan A, Caserta M, Dematteis A, Naso D, Mulatero P, Rabbia F, Veglio F. Baroreflex sensitivity is impaired in essential hypertensives with central obesity. J Hum Hypertens 2007; 21: 473-478.

7 Skrapari I, Tentolouris N, Perrea D, Bakoyiannis C, Papazafiropoulou A, Katsilambros N. Baroreflex sensitivity in obesity: relationship with cardiac autonomic nervous system activity. Obesity (Silver Spring) 2007; 15: 1685-1693.

8 Alvarez GE, Davy BM, Ballard TP, Beske SD, Davy KP. Weight loss increases cardiovagal baroreflex function in obese young and older men. Am J Physiol Endocrinol Metab 2005; 289: E665-E669.

9 Beske SD, Alvarez GE, Ballard TP, Davy KP. Reduced cardiovagal baroreflex gain in visceral obesity: implications for the metabolic syndrome. Am J Physiol Heart Circ Physiol 2002; 282: H630-H635.

10 Skrapari I, Tentolouris N, Katsilambros N. Baroreflex function: determinants in healthy subjects and disturbances in diabetes, obesity and metabolic syndrome. Curr Diabetes Rev 2006; 2: 329-338.

11 Alonso-Galicia M, Brands MW, Zappe DH, Hall JE. Hypertension in obese Zucker rats. Role of angiotensin II and adrenergic activity. Hypertension 1996; 28: 1047-1054.

12 Fredersdorf S, Thumann C, Ulucan C, Griese DP, Luchner A, Riegger GA, Kromer EP, Weil J. Myocardial hypertrophy and enhanced left ventricular contractility in Zucker diabetic fatty rats. Cardiovasc Pathol 2004; 13: 11-19.

13 Schreihofer AM, Mandel DA, Mobley SC, Stepp DW. Impairment of sympathetic baroreceptor reflexes in obese Zucker rats. Am J Physiol Heart Circ Physiol 2007; 293: H2543-H2549.

14 Lee SD, Magalang UJ, Krasney JA, Farkas GA. Opioidergic modulation of ventilatory response to sustained hypoxia in obese Zucker rats. Obes Res 2001; 9: 407-413.

15 Lee SD, Nakano H, Farkas GA. NMDA receptor-mediated modulation of ventilation in obese Zucker rats. Int J Obes Relat Metab Disord 2001; 25: 997-1004.

16 Lee SD, Nakano H, Farkas GA. Adenosinergic modulation of ventilation in obese Zucker rats. Obes Res 2005; 13: 545-555.

17 Lee SD, Nakano H, Farkas GA. GABAergic modulation of ventilation and peak oxygen consumption in obese Zucker rats. J Appl Physiol 2001; 90: 1707-1713.

18 Lee SD, Nakano H, Gosselin LE, Krasney JA, Schlenker EH, Farkas GA. Endogenous opioids modulate ventilation and peak oxygen consumption in obese Zucker rats. Am J Respir Crit Care Med 2000; 162: 1009-1015.

19 Pamidimukkala J, Jandhyala BS. Evaluation of hemodynamics, vascular reactivity and baroreceptor compensation in the insulin resistant Zucker obese rats. Clin Exp Hypertens 1996; 18: 1089-1104.

20 Bunag RD, Barringer DL. Obese Zucker rats, though still normotensive, already have impaired chronotropic baroreflexes. Clin Exp Hypertens A 1988; 10 (Suppl 1): 257-262.

21 Krontoradova K, Honzikova N, Fiser B, Novakova Z, Zavodna E, Hrstkova H, Honzik P. Overweight and decreased baroreflex sensitivity as independent risk factors for hypertension in children, adolescents, and young adults. Physiol Res 2008; 57: 385-391.

22 Potts JT. Inhibitory neurotransmission in the nucleus tractus solitarii: implications for baroreflex resetting during exercise. Exp Physiol 2006; 91: 59-72.

23 Wang JJ, Rong WF, Wang WZ, Zhang L, Yuan WJ. NMDA receptor mechanism involved in arterial baroreflex. Acta Pharmacol Sin 2000; 21: 617-622.

24 Dias AC, Vitela M, Colombari E, Mifflin SW. Nitric oxide modulation of glutamatergic, baroreflex, and cardiopulmonary transmission in the nucleus of the solitary tract. Am J Physiol Heart Circ Physiol 2005; 288: H256-H262.

25 Frigero M, Bonagamba LG, Machado $\mathrm{BH}$. The gain of the baroreflex bradycardia is reduced by microinjection of NMDA receptor antagonists into the nucleus tractus solitarii of awake rats. J Auton Nerv Syst 2000; 79: 28-33.

26 Nakano H, Lee SD, Ray AD, Krasney JA, Farkas GA. Role of nitric oxide in thermoregulation and hypoxic ventilatory response in obese Zucker rats. Am J Respir Crit Care Med 2001; 164: 437-442.

27 Viard E, Sapru HN. Carotid baroreflex in the rat: role of glutamate receptors in the medial subnucleus of the solitary tract. Neuroscience 2004; 126: 785-794.

28 Ohta H, Li X, Talman WT. Release of glutamate in the nucleus tractus solitarii in response to baroreflex activation in rats. Neuroscience 1996; 74: 29-37.

29 Miyawaki T, Suzuki S, Minson J, Arnolda L, Chalmers J, Llewellyn-Smith I, Pilowsky P. Role of AMPA/kainate receptors in transmission of the sympathetic baroreflex in rat CVLM. Am J Physiol 1997; 272: R800-R812.

30 Somers VK, Mark AL, Abboud FM. Interaction of baroreceptor and chemoreceptor reflex control of sympathetic nerve activity in normal humans. J Clin Invest 1991; 87: 1953-1957.

31 Matsuo I, Hirooka Y, Hironaga K, Eshima K, Shigematsu H, Shihara M, Sakai K, Takeshita A. Glutamate release via NO production evoked by NMDA in the NTS enhances hypotension and bradycardia in vivo. Am J Physiol Regul Integr Comp Physiol 2001; 280: R1285-R1291.

32 Cooper VL, Pearson SB, Bowker CM, Elliott MW, Hainsworth R. Interaction of chemoreceptor and baroreceptor reflexes by hypoxia and hypercapnia-a mechanism for promoting hypertension in obstructive sleep apnoea. J Physiol 2005; 568: 677-687.

33 Heistad DD, Abboud FM, Mark AL, Schmid PG. Interaction of baroreceptor and chemoreceptor reflexes. Modulation of the chemoreceptor reflex by changes in baroreceptor activity. J Clin Invest 1974; 53: 1226-1236.

34 De Ferrari GM, Sanzo A, Bertoletti A, Specchia G, Vanoli E, Schwartz PJ. Baroreflex sensitivity predicts long-term cardiovascular mortality after myocardial infarction even in patients with preserved left ventricular function. J Am Coll Cardiol 2007; 50: 2285-2290. 